\title{
Análisis y revisión del sarcasmo y la lítote: propuesta desde la Teoría de la Relevancia
}

\author{
Adrián Cabedo Nebot ${ }^{*}$ \\ Universitat de València, España
}

\begin{abstract}
Resumen
En general, el sarcasmo y la lítote han sido consideradas tradicionalmente como figuras retóricas y, por tanto, como usos dislocados del lenguaje. Desde la tradición clásica, se ha aceptado que existen dos tipos de lenguaje: el literal y el figurado. En tal sentido, este artículo pretende hacer un repaso a algunas consideraciones realizadas desde la Teoría de la Relevancia y, por tanto, concluir que existe un único lenguaje que depende de la relevancia comunicativa perseguida.
\end{abstract}

Palabras clave: relevancia, figuras retóricas, lítote, sarcasmo, ironía, lenguaje.

ANALYSIS AND REVIEW OF THE ROLE OF SARCASM AND LITOTE: A PROPOSAL FROM THE PERSPECTIVE OF THE THEORY OF RELEVANCE

Abstract

Overall, sarcasm and litote have been considered rhetorical figures and, therefore, dislocated uses of language. Classical studies accept

Para correspondencia dirigirse a: Adrián Cabedo Nebot (adrian.cabedo@uv.es), Departamento de Filología Española, Grupo Val.Es.Co, Facultat de Filologia, Universitat de València, Avda. Blasco Ibáñez, 3246010, València, España. 
the existence of two different languages: the literal one and the figurative one, whereas more recent theoretical frameworks, such as Relevance Theory, disagree with this standpoint. In that sense, this paper attempts to revisit some classical considerations from the perspective of Relevance Theory; one significant conclusion will be that there is only one language with different uses guided by communicative relevance.

Key words: Relevance Theory, Rhetoric, litote, sarcasm, irony, language.

Recibido: 31/03/09. Aceptado: 07/09/09.

\section{INTRODUCCIÓN}

Se pretende con este trabajo analizar y comentar dos fenómenos que han sido clasificados tradicionalmente como pertenecientes a la Retórica: el sarcasmo y la lítote. Se adoptará para tal estudio el punto de vista de la Teoría de la Relevancia, cuya base radica en que se utiliza un único lenguaje para la comunicación humana. No existen, por tanto, dos lenguajes, como se propone desde la visión tradicional; esto es, no hay un lenguaje literal y uno figurado, sino dos usos distintos dentro del mismo lenguaje. Cabe recordar que la perspectiva clásica (posiblemente circunscrita a obras de carácter retórico o literario) ha establecido una clara separación entre el lenguaje figurado y el literal; en principio, se trataría de dos lenguajes diferenciados (con códigos y normas diferentes para cada uno). Ahora bien, como se verá, es más simple postular la existencia de un único lenguaje (con un mismo código y unas mismas normas) que actúan en diferentes sentidos según la voluntad comunicativa.

En ese sentido, la motivación final de estos usos es la de conseguir comunicaciones óptimamente relevantes. Sobre todo, se incide en la idea de que lo que consiguen estos recursos retóricos es multiplicar las implicaturas débiles de los enunciados y conseguir con ello efectos poéticos, es decir, que lo que se transmita sea más rico y completo de lo que sería si se usara una forma literal o, lo que es lo mismo, si se hiciera coincidir la forma proposicional del enunciado con la del pensamiento.

Se ofrecerán, así pues, dos explicaciones sobre el sarcasmo y sobre la lítote a partir de dicha teoría. 


\section{TRES CONCEPTOS CLÁSICOS: IRONÍA, SARCASMO Y LÍTOTE}

Desde la antigüedad grecolatina se ha venido estudiando desde diferentes perspectivas la cuestión de las llamadas figuras retóricas. Así, la ironía se ha definido como la expresión de una idea mediante una palabra que significa lo contrario de esta (Lausberg 1984: 85). Así mismo, hay tres rasgos que caracterizan dicho tropo $^{1}$ :

1. La posibilidad de ser utilizada como elogio o vituperio.

2. Dirigida a personas o a uno mismo (autoironía).

3. La energía con la que se realice caracterizará seis tipos de ironía:

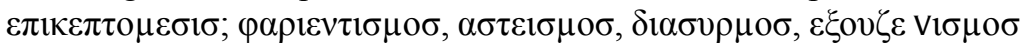
y, finalmente, $\sigma \alpha \rho \kappa \alpha \sigma \mu о \sigma$.

Así pues, desde este punto de vista, el sarcasmo no sería más que un tipo de ironía definido por una energía de emisión. Más en concreto, si la ironía está teñida de crueldad y hostilidad, se hablará de sarcasmo (Azaustre y Casas 1997: 90). Ej.:

E cuando llegó ante'l rey, venía tan desfaçiado por aquel golpe de travieso que traía por los ojos, que aspereza era grande de lo catar. Pero dixo el rey: ¡Ay sobrino de mal conde! ¡Creo que non seríades de aquí adelante para atalaya! (Libro del Caballero Zifar).

Por otro lado, puede parecer que incluir la lítote en un apartado dedicado a la ironía o al sarcasmo no sea coherente, sin embargo, la misma tradición dice que esto no es así. El mismo Lausberg define la lítote como una combinación entre el énfasis (figura retórica que lleva de lo impreciso a lo preciso) y la ironía. En esa línea, con la lítote se conseguirá un grado máximo de significado mediante la aparente negación de lo contrario. Mediante la sugestión que consigue la figura retórica se evita emitir una ostentación exagerada en el medio expresivo. La lítote, así pues, expresa una cierta gradación, como veremos más adelante. Ej.:

$$
\begin{gathered}
\text { Dios dé su gloria a Boscán } \\
\text { y a Garcilaso poeta, } \\
\text { que con no pequeño afán }
\end{gathered}
$$

\footnotetext{
${ }^{1}$ El tropo consiste en el uso de una palabra inapropiada para designar un concepto.
} 


\section{y por estilo galán}

sostuvieron esta seta

(Cristóbal de Castillejo, Reprensión contra los poetas españoles que escriben en verso italiano).

En la actualidad, y de acuerdo con las nuevas teorías lingüísticas, hay otras explicaciones. Así, los hay que siguen distinguiendo entre lenguaje literal y lenguaje figurado, como planteaba Grice. Para este, un enunciado irónico consistía en quebrantar la máxima de calidad (No diga aquello que crea falso), pues se acepta que lo codificado en el enunciado y lo que se quiere transmitir es distinto y únicamente recuperable mediante la acción de las llamadas implicaturas. De este modo, se puede abogar fácilmente por un lenguaje poético o por una retórica que le da un matiz a las palabras distinto del que habitualmente poseen en la conversación cotidiana. Ahora bien, uno de los problemas de Grice es que en los enunciados irónicos, por ejemplo, no siempre se da el hecho de que se esté incumpliendo la máxima de cualidad. En otro sentido, con la lítote pasa algo semejante, si bien parece que la máxima que se quebranta no es la de calidad, sino la de modo (Sea preciso, evite las expresiones oscuras, etc.).

Giora (1995), por su parte, propone que en los enunciados irónicos opera una negación indirecta que puede recuperarse al observar el contenido implícito del enunciado. Así pues, el conocido ejemplo de iQué calor! dicho en invierno a cinco grados de temperatura se debería entender por No hace calor.

Así mismo, es también interesante la postura de Jorgensen (1996) respecto a la ironía y al sarcasmo, ya que su posicionamiento está vinculado a la politeness theory (teoría de la cortesía). Para esta autora, y en cierto sentido también para Brown y Levinson, el sarcasmo es un mecanismo que salvaguarda, de algún modo, la imagen social del hablante en un ámbito de familiaridad o de amistad. Con ella, se evita la brusquedad del pensamiento explícito. Estaría, por tanto, en una línea parecida al indirectness (contenido indirecto) al que alude Giora (1995). Ej.:

Tú y tu compañero de clase habéis estado hablando acerca de antiguas novias, particularmente de tu antigua novia María:

Tú dices, "Odio el hecho de que mi nueva novia pueda estar pensando en su ex"

Tu compañero dice en un tono crítico:

(Versión sarcástica) "Desde luego, porque tú nunca piensas en María, ¿verdad?" 
(Versión directa) "Desde luego, pero ten en cuenta que tú también estás siempre pensando en María” (Jorgensen 1996: 630)².

Levinson, sin embargo, propone que en un enunciado irónico se viola la heurística $\mathrm{M}$, es decir, aquella que estipula lo siguiente: What is said in an abnormal way isn't normal. En realidad, al distinguir la dicotomía normal/ anormal incide de nuevo en la distinción entre lenguaje literal y lenguaje figurado que se comentaba antes. Esto supone que existen usos dislocados del lenguaje y que nuestra mente conceptúa en dos vertientes: la habitual y la no habitual. Respecto a las lítotes ocurre lo mismo. El hablante acude a una forma anormal (expresar la negación del contrario de lo que se quiere expresar) para transmitir algo que podría haber transmitido con un lenguaje literal. Ej.: puede decirse directamente mucho y, sin embargo, el hablante prefiere utilizar la secuencia no poco. Esto se explica por la voluntad retórica del emisor.

Hasta ahora, las explicaciones planteadas parecen coherentes y, en realidad, lo son. Aun así, el problema radica en explicar por qué un hablante común (no un poeta ni un erudito) se decanta por formas que integran la rama llamada Retórica. ¿Por qué alguien usa metáforas en su conversación? ¿Por qué alguien decide decir lo contrario de lo que piensa? Se podrían hacer infinitas preguntas de este tipo sobre la motivación que condiciona la actuación de los hablantes, sin embargo, no se acertaría a dar con una respuesta exacta.

En tal sentido, una de las teorías que ha intentado acercarse a esta cuestión ha sido la Teoría de la Relevancia, creada por Sperber y Wilson (1994). Desde su óptica, el uso de un lenguaje figurado o de un lenguaje literal está motivado por la consecución de la relevancia. El oyente debe entender que la forma lingüística del mensaje es la más adecuada (la óptimamente relevante) para llegar al pensamiento del hablante. Así pues, más que de dos lenguajes, debería hablarse de dos usos dentro del mismo lenguaje, que vendrían marcados por la interpretación o representación de los enunciados. En unos casos se hablaría de una descripción (por ejemplo, las aserciones) y, en otros, de la interpretación del pensamiento (por ejemplo, las metáforas). En el primer caso, el enunciado enlaza con un estado de cosas, es decir, con la realidad. En el segundo caso, el enunciado enlaza con un pensamiento del

\footnotetext{
2 Este ejemplo que aporta la autora parece más bien un caso de ironía típico, donde lo que se ecoiza es un supuesto pensamiento del compañero de habitación que sería algo así como [Yo no pienso nunca en mi ex]; a no ser que la actitud del emisor fuese explícitamente dañar o molestar a su interlocutor, lo cual no parece que sea el ejemplo de este caso preciso.
} 
hablante. Hay que ir con cautela al respecto porque, desde una perspectiva kantiana, todo pasa por los sentidos y, por tanto, también por la mente. Véase un ejemplo:

(1). Juan tiene almorranas. [P] se enlaza con el hecho contrastivo de que [P].

(2). Juan tiene almorranas. [P] se enlaza con el hecho subjetivo de que [T].

El primer uso sería un uso literal, el segundo tendría un uso metafórico. En el segundo caso, $[\mathrm{T}]$ podría ser, por ejemplo, que Juan está enfadado u otro significado similar. Por otro lado, las implicaturas débiles que se obtienen de la emisión de 2 no se obtienen según la manifestación explícita de la forma proposicional [Juan está enfadado]. Esto es lo que Sperber y Wilson denominan efecto poético. Todo lo que el hablante quiere transmitir no puede hacerse con la consonancia entre la forma proposicional del enunciado y la del pensamiento; se despiertan una serie de implicaturas (o quizá connotaciones) que no se obtendrían de otro modo que no fuera la expresión de una oración donde hay dos formas proposicionales: la del enunciado y la del pensamiento.

No obstante, en ambos procesos hay una interpretación y, por tanto, el procedimiento comprensivo en el uso literal es el mismo que se utiliza en el uso figurado. El decantarse por elegir uno u otro vendrá condicionado siempre por la búsqueda de una óptima relevancia comunicativa. Lo literal y lo figurado, por tanto, no son dos clases distintas de lenguaje, sino puntos extremos en una escala (Pons 2004: 57).

Por tanto, se puede ver el sarcasmo como un subtipo de ironía que envuelve cualquier expresión de una actitud displicente y agria. Por ello, lo irónico (y lo sarcástico) no está tanto en la expresión como en la actitud de disociarse del enunciado ecoizado. Otro aspecto interesante es el de que en la ironía no siempre es necesario que hablante y oyente sean conscientes de la actitud irónica, mientras que el sarcasmo sí parece exigir el conocimiento de la actitud por ambas partes. Atiéndase al ejemplo que expresa Hamamoto (1998: 262) respecto de una ironía en la que el emisor no expresa el enunciado como irónico, pero que el oyente sí interpreta como tal:

La comida favorita de Taro es el Tira-mi-su. Hanoko, que no sabe que es su comida preferida, le dice:

Hay gente que todavía come Tira-mi-su. Es increíble, ¿no?

En cuanto a la lítote, parece que opera un criterio similar. El hablante, en aras de una comunicación óptimamente relevante, intenta buscar la forma de expresarse que mejor represente su pensamiento. En este sentido, la negación 
de lo contrario tiene una serie de implicaciones y de precisiones semánticas que se comentarán más adelante.

Por lo tanto, tanto la ironía, el sarcasmo y la lítote son casos en los que la forma proposicional del enunciado no suele coincidir con la forma proposicional del pensamiento. La tradición retórica ha optado por ver en este sentido casos especiales y constitutivos de un lenguaje marcado y diferente del habitual. Por otro lado, Sperber y Wilson (1990) optan por pensar que en la comunicación el hablante utiliza un único lenguaje que maneja según su conveniencia para expresar del mejor modo posible su pensamiento.

\section{ECHOIC MENTION OR INTERPRETATION}

Sperber y Wilson (1986 ápud Livnat 2003:72) definen la 'echoic interpretation' como "the use of a propositional form to represent not itself but some other propositional form it more or less closely resembles".

Consideran que en toda ironía no se da a entender lo contrario de lo que se dice, sino que se presenta un significado 'ridículo o inadecuado' a la situación y se evoca otra enunciación en que eso se habría dicho en serio (Torres Sánchez 1999: 439)3. Esta mención o interpretación ecoica que ellos proponen puede reproducir lo dicho por otra persona, ser repetición de la opinión de un determinado grupo, tener una fuente imaginaria, etc.

Así, Sperber y Wilson (1994) vienen a señalar que todo enunciado se usa para representar un pensamiento del hablante. Este puede ser una descripción o una interpretación, como hemos dicho anteriormente. En el caso de la ironía se trataría de la relación entre el pensamiento del hablante y el pensamiento atribuido a otro (o al mismo hablante en el pasado).

La ironía verbal es en realidad una variedad de enunciado ecoico implícito. No existen a priori marcas verbales que identifiquen un contenido irónico, a no ser construcciones forzadas como "Hablando irónicamente...". En consecuencia, la actitud irónica debe deducirse entonces por la kinésica, por la entonación o por supuestos contextuales. Donde sí pueden encontrarse casos de marcas explícitas es, por ejemplo, en el lenguaje escrito. Piénsese en el lenguaje que utilizamos en el chat. Una secuencia como la siguiente

\footnotetext{
Salvatore Attardo tiene una formulación parecida en su 'Irony as a relevant inappropriateness' $(2000)$.
} 
vendría determinada en sentido irónico por un emoticono (imagen icónica que sustituye una emoción) o por una explicitud formal:

Pepe_26: Eres lo peor del mundo, (-)

Julia_tanguita: Pues tú eres un atuténtico gigoló (ironía)

La explicitud (ironía) de Julia_tanguita indica que no está segura de que su interlocutor vaya a interpretar correctamente su mensaje. Hay que pensar que en Internet hay un presente como en la conversación cotidiana, sin embargo, hay muchos rasgos que no están presentes, entre ellos muchos de los que ayudan a descubrir la ironía (entonación, gestos, etc.) Por tanto, un internauta hará uso de estos recursos para conseguir una comunicación óptimamente relevante.

En otro sentido, Seto (1998) cuestiona la definición de la ironía como enunciado ecoico. En el siguiente apartado veremos que Wilson lo rebate con especial maestría y que de todas las teorías expuestas anteriormente la de los enunciados ecoicos parece la más coherente.

Si se acepta ironía (y por ahora sarcasmo) como un tipo de enunciado ecoico se debe concluir que no hay ninguna relación entre este tipo de uso del lenguaje y el que representa la lítote. Pero atiéndase a estas palabras: "Ahora nos gustaría demostrar que la ironía y una serie de tropos relacionados con la misma (por ejemplo, la meiosis o la lítote) se pueden agrupar en una serie de casos que normalmente no se considerarían en absoluto ejemplos del lenguaje figurado. Lo que une a estos casos es el hecho de que el pensamiento del hablante interpretado por el enunciado es una interpretación" (Sperber y Wilson 1994: 290).

\subsection{IRONÍA Y SARCASMO}

Para reconocer un enunciado como irónico se deben tener en cuenta tres aspectos (Sperber and Wilson 1994: 292):

1. Reconocer el enunciado como ecoico

2. Identificación de la fuente

3. Reconocer la actitud de desaprobación del hablante respecto de la opinión ecoica.

Si no se entienden con propiedad estos puntos se puede incurrir en algunos errores como los que comenta Seto (1998: 239-255). Atiéndase al siguiente ejemplo: 
El hablante A dice [iQué fresquito!] cuando en realidad hace muchísimo calor. Pensemos que esto ha sido dicho a las doce de la mañana de un veinticinco de julio y en la playa. A las siete de la mañana el hablante había estado hablando con un amigo que señalaba de modo literal que hacía algo de frío con la secuencia [iQué fresquito!]. Lo que hace A luego es mantener una actitud disociativa del pensamiento ecoizado que había mantenido B unas horas antes.

Pero, ¿debe ser el eco una repetición exacta de las palabras de una fuente precisa? No siempre es así. Dicen Sperber y Wilson (1998: 284): "the notion of echo we used in analysing irony is a technical one; it is deliberately broad, and goes beyond what would generally be understood by the ordinarylanguage word echo".

El problema de aumentar el campo de actuación de la palabra eco es peligroso porque, en realidad, cualquiera de nuestros enunciados puede ser considerado repetición de algo dicho en otro momento de nuestra vida. En tal sentido, Sperber y Wilson (1998) defienden que ese eco debe estar de algún modo patente en la mente del hablante.

Así pues, no hay una línea férrea entre la ironía y otros fenómenos como, por ejemplo, la metáfora. Ambos son interpretaciones de un pensamiento del hablante que, en principio, difiere de la forma proposicional del enunciado emitido. En la ironía se da la peculiaridad de que ese pensamiento es a su vez interpretativo en segundo orden.

En el anterior ejemplo, por tanto, las fuentes pueden ser diversas. Imagínese por ejemplo que no exista ningún momento reciente en que un hablante anterior haya dicho $[\mathrm{P}]$ en serio y, sin embargo, no exista duda de que [P] sea irónico. Por ejemplo, un hablante deambula por la playa sin camisa $\mathrm{y}$ medio ahogado por el calor que hace. No hay nadie a su alrededor $\mathrm{y}$, sin embargo, emite $[\mathrm{P}]$ con un claro sentido irónico. Autores como Hamamoto (1998) o el propio Seto (1998) cuestionarían que este enunciado fuera irónico y hablarían de una ironía no-ecoica. A nuestro juicio esto no sería necesario. Préstese atención a la figura número 1: 


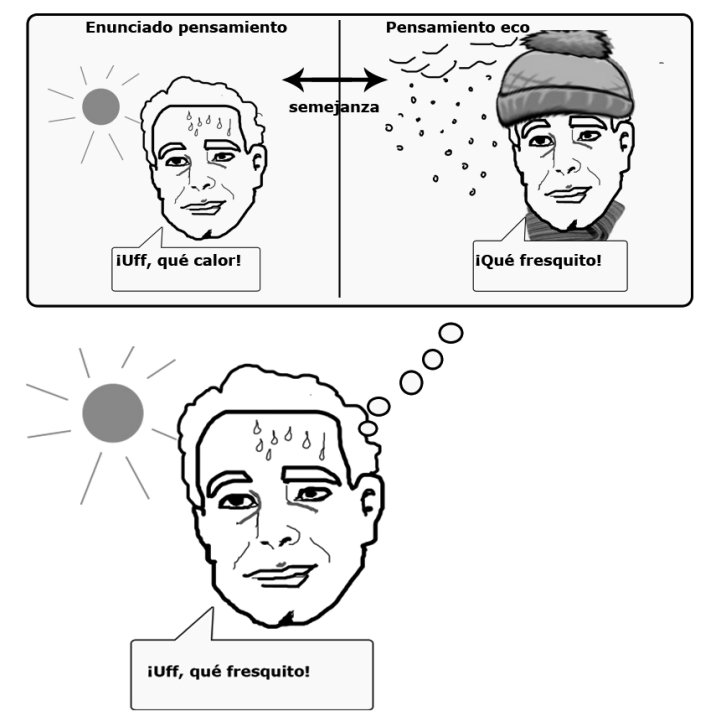

Fig. 1

La fuente del enunciado ecoico es el mismo hablante en el pasado. La forma proposicional de [P] no sería Enrique piensa que [P], sino exactamente $\mathrm{S}$ se disocia de [S' piensa que [P]]. En este caso, Enrique sería S y el Enrique del pasado sería S'. Matizando un poco la propuesta de Curcó (2000) podría esgrimirse un esquema como el siguiente (Curcó 2000: 269):

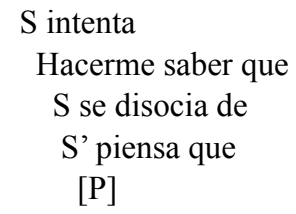

Vamos a comentar, a continuación, los ejemplos que aporta Hamamoto (1998) donde indica que existe una cierta 'vaguedad de la fuente". De esta manera, cabe tener en cuenta que todos los ejemplos de ironía (o sarcasmo) no son tan claros como el anterior, en el que la fuente era identificable y en el que el enunciado era una repetición exacta de un enunciado anterior (real o mental). Por otro lado, en dicho ejemplo, lo dicho es en realidad lo contrario de lo que se piensa, con lo que se estaría dando razón en ese sentido a la tradición clásica. Luego se verá que no es así, aunque no cabe duda de que en el grueso de los enunciados irónicos se dice lo contrario de lo que se piensa con gran asiduidad. 
Señala Hamamoto (1998) el siguiente ejemplo:

Una muchacha entra con el pelo despeinado por la acción del viento y un compañero le dice [Me gusta tu nuevo peinado, estás muy guapa]

Evidentemente, el verdadero pensamiento del compañero sería [Estás despeinada] o [Vas hecha un desastre]; si fuera sarcasmo podrían ser cualquiera de estos pensamientos, pero con la intención de dañar la imagen el receptor (en términos de cortesía), en este sentido serían más apropiados pensamientos como [Debería darte vergüenza ir asi], [Estás horrible], etc. En otro orden de cosas, tampoco hay ninguna fuente reconocible en principio. Sin embargo, la noción de eco en el sentido en el que lo utilizan Sperber y Wilson (1998) ha ido extendiéndose y, de este modo, el emisor podría hacerse eco de un pensamiento común según el cual es cortés y respetuoso halagar a una mujer por un peinado o look distinto. Como puede observarse, el emisor $\mathrm{S}$ no quiere decir lo contrario de lo que expresa, es decir, su intención no es decir [No me gusta tu nuevo peinado], sino [Estás despeinada], por ejemplo. Lo único de lo que se disocia este enunciado para ser irónico es del hecho de que una norma social imponga alabar unas cualidades cuando estas son inexistentes. Obsérvese la figura 2:

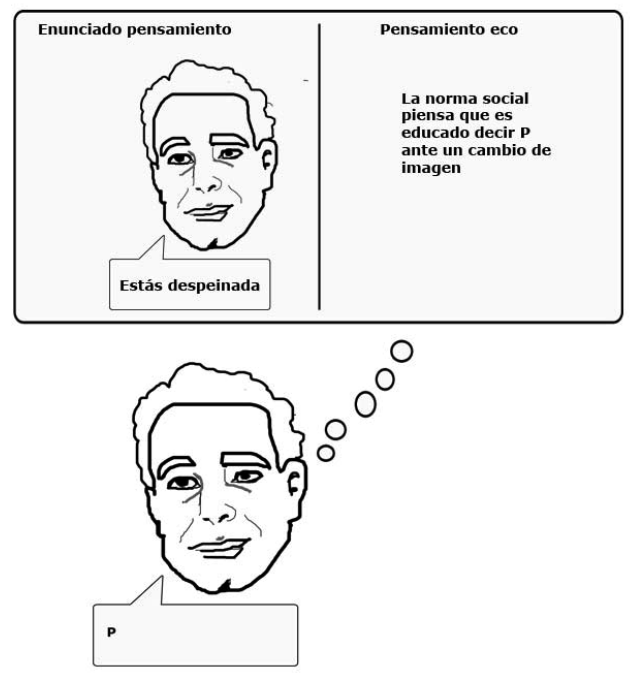

Fig. 2 
Otro ejemplo que esgrime Hamamoto (1998) es el del hijo de unos padres activistas preocupados por el medioambiente pero que tienen su casa muy desordenada. Este chaval dirá: [Mi casa es un medio ambiente].

La explicación que da Wilson es que los padres deben de pensar que se preocupan por el medioambiente. En realidad, aquí podemos observar que se compaginan dos fenómenos. En principio, existe una metáfora que presenta el término medioambiente como sinónimo no únicamente de casa, sino también de lugar desordenado o desprotegido. Estos contenidos son desvelados mediante la comprensión de implicaturas débiles, como se ha expuesto anteriormente en cuanto a los efectos poéticos de los enunciados.

Por tanto, de lo que se disocia $\mathrm{S}$ no es de $[\mathrm{P}]$ sino de una de las implicaturas débiles implícitas enciclopédicamente en la palabra medioambiente; esto es, que sus padres piensan que se preocupan por el medioambiente. Como puede observarse en la figura 3 , el fenómeno de la ironía no es un fenómeno sencillo. No basta con decir que $\mathrm{S}$ se disocia de la opinión ecoizada, sino que hay que saber exactamente de qué se disocia. Por otro lado, puede observarse en este ejemplo claramente irónico que $\mathrm{S}$ no intenta decir lo contrario de lo que expresa, es decir, no quiere transmitir [Mi casa no es un medio ambiente] sino una actitud disociativa a partir de unas implicaturas débiles generadas por la metáfora.

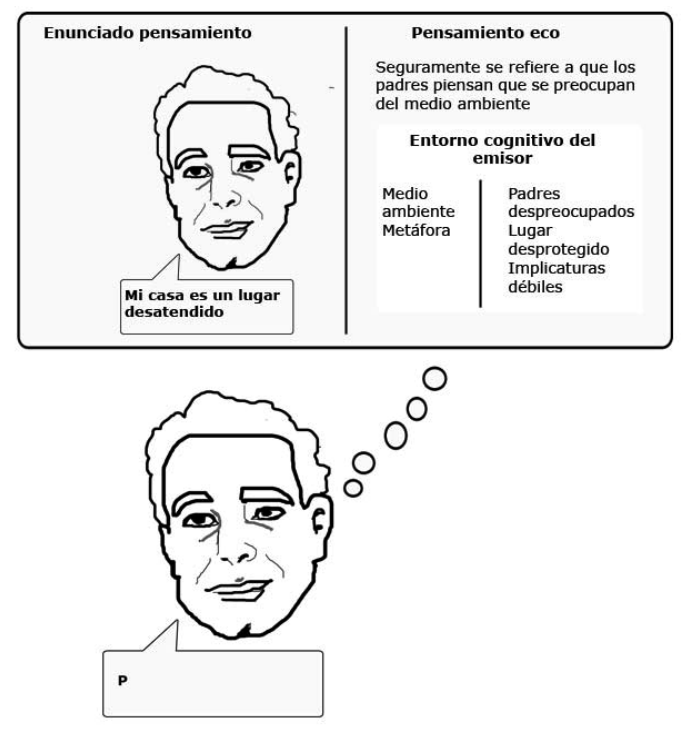

Fig. 3 
Hasta ahora, se han comentado casos de ironía pura, la que se comenta habitualmente en la mayoría de artículos que enfocan dicho suceso desde el ámbito de la relevancia. La pregunta que cabe hacerse es si ironía y sarcasmo son la misma cosa.

Por lo que se ha observado, el punto clave para descubrir el sentido irónico no está únicamente en reconocer un enunciado ecoico y su fuente, sino que es muy importante reconocer la actitud. Como no hay marcas lingüísticas específicas, es difícil precisar desde un punto de vista del lenguaje la delimitación de algo tan vago y cambiante como la actitud. En sentido estricto, cualquier enunciado podría ser irónico con la actitud debida (para ello debería operar siempre sobre una opinión ecoica).

Más que sugerir que el sarcasmo se debe a una actitud cruel y despiadada que opera sobre el receptor, habría que ir paso a paso. En primer lugar, hay que actuar como en cualquier enunciado irónico y descubrir la opinión ecoica, la fuente y luego el tipo de actitud. Si el sarcasmo es una variedad de la ironía, debe aceptarse que la actitud también será disociativa pero desde otra perspectiva. En la ironía, bastaba con que uno de los interlocutores percibiese el enunciado como irónico, mientras que en el sarcasmo parece condición indispensable que ambos lo reconozcan.

Según la visión social, habría que sugerir que el sarcasmo atenta contra la imagen del receptor. Es manifiesta la actitud de enfrentarse frontalmente contra la estabilidad emocional del receptor. De nuevo, hay que diferenciar una gradación: no es lo mismo el sarcasmo entre amigos, que puede ser agradable, que el sarcasmo con gente extraña, donde se produce una sensación de malestar. Por tanto, se puede intentar dañar al otro con un fin positivo (en sentido bromista) o con un fin negativo (molestar). En cualquier sentido, esa actitud de dañar la imagen del receptor debe ser reconocida y debe hacerse patente.

Piénsese en los siguientes ejemplos:

A) Juan y Eva han tenido una discusión hace media hora y ahora se están vistiendo para ir a una fiesta. Mientras se están cambiando en la habitación, Juan le dice a su novia: ¿Para qué llevas sujetador? A lo que ella responde: Y tú, semental, ¿para qué usas calzoncillos?

B) Juan y Eva llegan borrachos a casa y se están desvistiendo para hacer el amor. Juan, bromeando, le dice: ¿Para qué llevas sujetador? A lo que ella responde entre risas: Y tú, semental, ¿para qué llevas calzoncillos?

En ambos casos se aprecia el sarcasmo. La ironía ha sido dicha para dañar, pero mientras en A se decanta hacia una carga negativa del impulso sarcástico, en B opera la carga positiva. Por tanto, en un caso el fin será 
molestar y enojar, mientras que en el otro será un típico bromear entre parejas.

En el caso de A, el emisor S puede hacerse eco de un pensamiento de su mujer según el cual ella está muy acomplejada por su poco pecho, pero piensa que tiene todo el derecho para llevar sujetador. También podría hacerse eco de un pensamiento común en la sociedad, según el cual una mujer de grandes pechos tiene más derecho que una que apenas tenga para llevar sujetador, pero aun y así se respeta socialmente que estas últimas lleven sujetador. Como puede observarse, en ambos casos se trata de un pensamiento sexista totalmente reprobable.

Evidentemente, la repuesta de Eva sigue el mismo camino que el enunciado de su novio, aunque en esta ocasión está aludiendo al tamaño de sus atributos. En realidad, el pensamiento del que el emisor se hace eco no siempre tiene por qué existir, sino que puede ser sugerido o supuesto; por ejemplo, el emisor de A se hace eco de un pensamiento supuesto de su novia, pues a lo mejor no tiene la certeza de que lo tenga. En su intención de molestar y enfadar, el emisor elige el supuesto ecoico que le parece que puede provocar más daño. Obsérvese la siguiente figura:

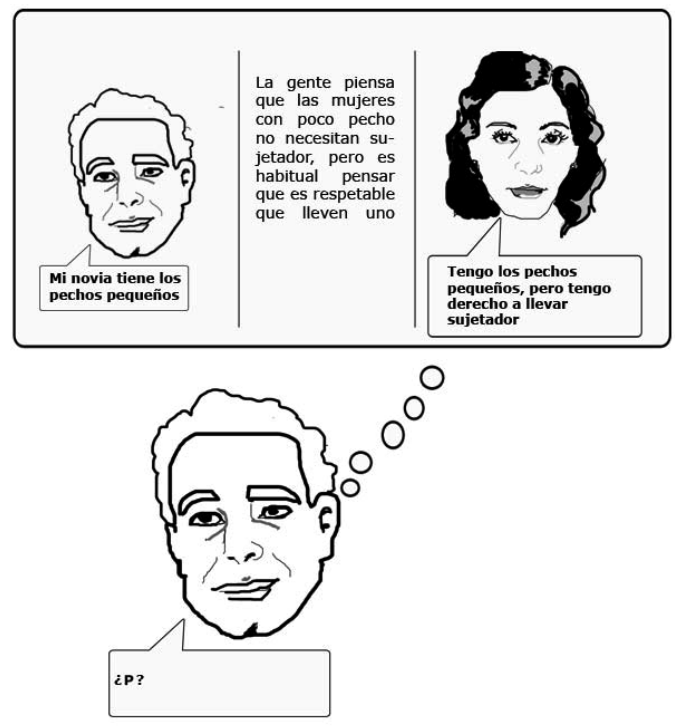

Fig. 4

Piénsese ahora en el siguiente caso que tiene que ver con lo expuesto anteriormente. Imaginemos que el pensamiento de Eva es [Tengo los pechos pequeños pero tengo derecho a llevar sujetador]. Juan sabe que 
este es el pensamiento de su novia, pero su intención deja de ser sarcástica para convertirse en burla. Al pensamiento que tiene su novia le añadiría lo siguiente [tengo derecho a llevar sujetador aunque sé que en realidad no me hace falta]. Con lo cual, la burla lo que haría sería asociarse con un supuesto pensamiento ecoico atribuido a otro (persona, institución, sociedad, frase proverbial, etc.).

De todas maneras, hay quien tiende a meter en la misma taxonomía a la ironía, el sarcasmo y la burla. Sin embargo, cabe pensar que en un caso hay una disociación clara, mientras que en el caso de la burla parece que lo que existe es una confirmación de un supuesto atribuido que sabemos que puede molestar.

Se establece, a continuación, otro caso de sarcasmo:

Juan y Eva se encuentran ahora de viaje por el campo. Han vuelto a discutir hace media hora y Juan está buscando la manera de crispar a su novia. En ese instante su coche pasa por delante de un campo donde hay toros y vacas pastando. Juan dice a su novia: Mira, familiares tuyos. A lo que ella responde: Sí... imis suegros!

Juan piensa o que la familia de Eva es insoportable o que su novia es insoportable y no encuentra mejor símil que asociarles con un grupo de toros y vacas que pastan en el campo. El pensamiento del que se hace eco y del que se disocia es un posible pensamiento de su novia de que: o sus familiares son buenos o que ella es una buena persona. De nuevo, la actitud manifiesta es machista, cruel y, por ello, reprobable.

La respuesta de Eva le da una vuelta de tuerca a la amenaza de imagen que propone el enunciado de su novio. En ambos enunciados, hay una metáfora a la que se añade una actitud irónica. Así pues, para Eva sería la familia de Juan o el mismo Juan los que son insoportables. Con ello consigue múltiples implicaciones débiles que no habría conseguido diciéndole [Eres insoportable/Tu familia es insoportable]. Las implicaturas podrían ser tales como: eres sucio, eres bobo, tienes un temperamento fuerte o vago (según se tome como referencia la toro o a la vaca), eres un cornudo, tus padres eran infieles, etc. 


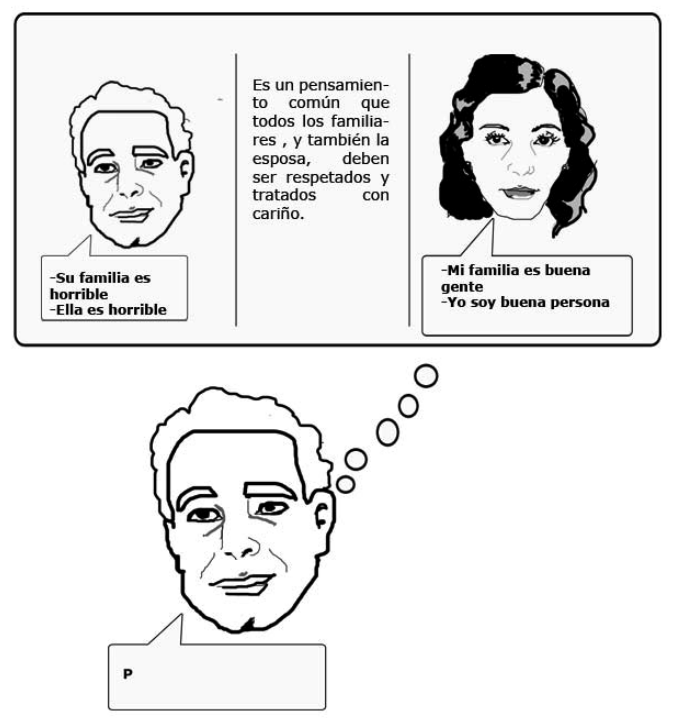

Fig. 5

Así pues, a los tres rasgos básicos que operan sobre la ironía habría que añadir un rasgo más:

1. Reconocer un enunciado ecoico

2. Reconocer la fuente

3. Reconocer una actitud disociativa respecto a la opinión ecoizada

4. Reconocer que se intenta dañar la imagen del interlocutor, que debe ser a su vez consciente del daño que recibe.

La dificultad de graduar una mayor o menor energía (de modo cercano a lo que exponía Lausberg 1984) no siempre es discernible con claridad. Más bien, lo que existe es un continuo con distintos matices de actitud y emoción que dan pie a toda una gama de casos límite que no encajan claramente en ningún esquema predefinido (Sperber y Wilson 1994: 293; Yamanashi, 1998). Cabe considerar, no obstante, la existencia del rasgo "dañar la imagen del interlocutor", que parece sugerir que el sarcasmo sí existe como uso específico dentro del campo más general de la ironía. De esta manera se intenta que algo gradual e inespecífico como una energía se consolide como rasgo identificativo. Por el momento, en todos los ejemplos que se han observado sí parece corroborarse. 


\section{2. ¿ES LA Lítote UN ENUNCIADO ECOICO?}

Parafraseando lo que se explica en la Teoría de la Relevancia podría decirse, como se ha señalado anteriormente, que todo enunciado representa un pensamiento y que este puede ser una interpretación (de un pensamiento atribuido o deseable) o una descripción (de un estado de cosas real o deseable) (Sperber y Wilson 1994: 282-283).

No se entiende que la lítote indique ningún tipo de deseo más que el de que sea un recurso suficiente para conseguir una óptima relevancia comunicativa. Por tanto, debe ser una interpretación o una descripción. En el primer caso, entrarían dos planos mentales: el del pensamiento verdadero y el del pensamiento atribuido; en el segundo caso, existiría un único plano mental que podría corroborarse con la realidad aprehensible. Véase la siguiente figura:

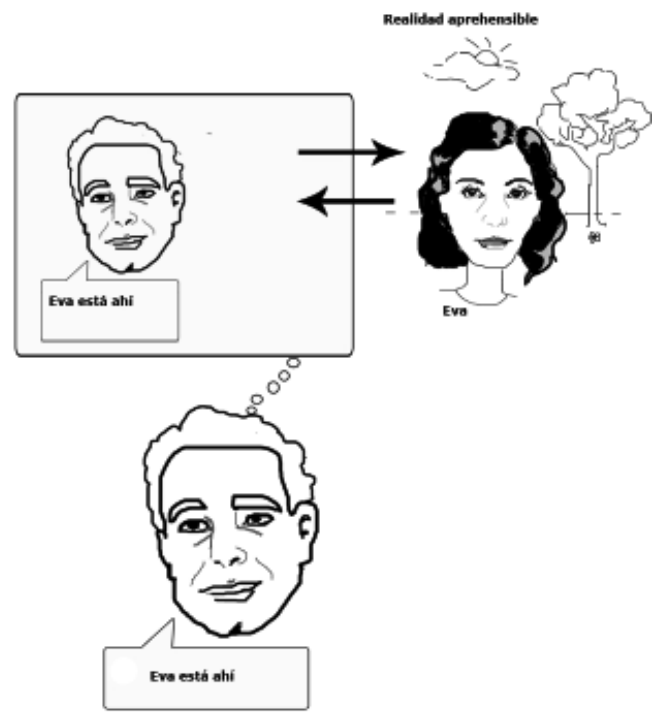

Fig. 6

En esta figura, puede observarse que la forma proposicional del enunciado y la del pensamiento son la misma. Por ejemplo: Enrique piensa que $\mathrm{P}$, Enrique afirma que $\mathrm{P}$, etc.

En un caso de pensamiento atribuido, se podría aludir como ejemplo cualquiera de las figuras expuestas anteriormente que versaban sobre la cuestión de la ironía y del sarcasmo. Nos gustaría, a continuación, volver a repetir uno de los rasgos que utilizaba Lausberg (1984: 87) para definir la 
lítote: "El énfasis de la lítote consiste en la plenitud gradual de la significación mentada, que se expresa mediante una formulación más amplia, pero gradualmente inferior". Véase cómo puede aplicarse esto a ejemplos en los que la negación acompaña a un adyacente de índole cuantitativa. $\mathrm{Ej}^{4}$.:

1. conmigo, antes me hizo que metiesse las manos y, no mucho cortés, topando unos andrajos en vez de saya ** 1626 Céspedes y Meneses, Gonzalo de Varia fortuna del soldado Píndaro ESPAÑA 12. Relato extenso novela y otro Arsenio Pacheco, Espasa-Calpe (Madrid), 1975.

2. a nombrados seran. Cierta forma fue introduzida e no sin raçon en tiempos passados cerca las manlieutas ** 1414 Anónimo Ordinación dada a la ciudad de Zaragoza por el rey don Ferna ESPAÑA 10. Ordenamientos y códigos leg Manuel Mora Gaudó, Impr. Mariano Escar (Zaragoza), 1908.

3. éndolos cogido la bandera y muerto algunos aunque no con poco daño suyo, pues perdió su sargento, D. Fr ** 1773Victoria, Fray José Documento inédito [Documentos indispensables para la verdade FILIPINAS 10]. Documentos notariales Eduardo Navarro, Imprenta del Asilo de Huérfanos (Madrid), 1908.

4. ria, caminaron el Caballero del Sol y el salvaje, no con mucho trabajo por ser espaciosa y llana aunque ** 1552 Hernández de Villaumbrales, Pedro Peregrinación de la vida del hombre ESPAÑA 12. Relato extenso novela y otr Biblioteca Virtual Cervantes, Universidad de Alicante (Alicante), 2003.

5. los miserables despojados. Todo lo cual miraban, no sin mucho dolor, los dos hermanos, dando gracias a**1613 Cervantes Saavedra, Miguel de Las dos doncellas [Novelas ejemplares] ESPAÑA12.Relato breve culto Florencio Sevilla Arroyo; Antonio Rey Hazas, Centro de Estudios Cervantinos (Alcalá de Henares), 1994.

6. desenreda la cabellera de oro, le hace la coleta, con no poco arte, y le pone el castor panzadeburro. $T * * 1928$ Carrasquilla, Tomás La marquesa de Yolombó COLOMBIA12. Relato extenso novela y otro Kurt L. Levy, Ayacucho (Caracas), 1984.

7. ian por ambas partes, por Poniente y por Levante, con no mucho mar en medio; porque desde el estrecho $d * *$ 1604-1618 Sandoval, Fray Prudencio de Historia de la vida y hechos del Emperador Carlos V ESPAÑA 19. Historiografía Universidad de Alicante (Alicante), 2003. 
El ejemplo que pone Lausberg (1984) en su manual es el siguiente: cuando se dice no pequeño y se intenta transmitir muy grande. Esto sería observable en adjetivos de tipo gradual como el que utiliza en su ejemplo. Sin embargo, aquí se pretende atender a un tipo de construcción distinta, como ya se ha dicho, que podría esquematizarse del siguiente modo:

\section{$\mathrm{NO}+[$ ADYACENTE CUANTITATIVO + SUSTANTIVO]}

En algunos casos, la situación se complicará con la aparición de preposiciones de índole cuantitativa (entiéndase con y sin). Y se dice que se complica porque será complicado observar si la negación opera sobre la preposición o sobre el adjetivo cuantitativo. Por ejemplo, en una secuencia como [con no poco arte], podría intentarse transmitir una especie de lítote de segundo grado conseguida mediante la preposición privativa: [sin poco arte]; por el contrario, también podría ser el caso de que la negación incidiera directamente sobre el adjetivo cuantitativo: [con mucho arte]. Lausberg (1984), a partir de lo visto, precisaría este último pensamiento de este modo: [con muchísimo arte].

Piénsese en el siguiente ejemplo:

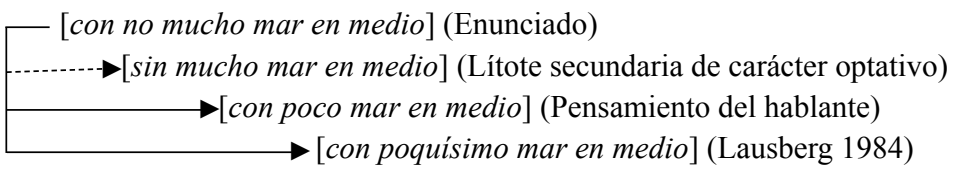

La forma proposicional del hablante no es igual a la expresada en el enunciado, lo cual debería acercarnos a un uso figurado del lenguaje en aras de una comunicación óptima. El emisor sabe que todo lo que quiere transmitir solo puede ser transmitido mediante el uso de este recurso llamado lítote.

Decía Lausberg (1984) que la lítote es un punto intermedio entre el énfasis y la ironía. Ya hemos clarificado antes que la ironía no tiene por qué ser siempre la negación de lo que se piensa. Por otro lado, el énfasis es un procedimiento mediante el cual lo impreciso se hace preciso.

En esa línea, en el significado de una palabra no solo se incluye su objeto referencial correspondiente, sino también todas las asociaciones que provoca; un poco en la línea de los efectos poéticos que mencionábamos en el anterior punto. Por ello, cualquier enunciado puede ser parafraseado, pero pierde en ese cambio muchos efectos que se recuperan en la forma original. La gente apunta a la relevancia máxima y por ello en ocasiones se ve forzada a utilizar recursos como la lítote, la ironía o cualquier otra de las llamadas figuras retóricas (Sperber y Wilson 1990: 140-144). 
Ahora acéptese el siguiente supuesto. Acéptese que cuando un hablante elige la forma [no + adyacente + sustantivo] no lo hace buscando algún efecto o connotación especial, sino que está siendo literal, es decir, que está describiendo un estado de cosas de la realidad. Volvamos sobre el ejemplo 7: ¿cuánto abarca no mucho en esta secuencia? En la línea de Lausberg (1984), hay que sugerir que existe una imprecisión delimitadora por algo que veremos a continuación. Véase la siguiente figura:

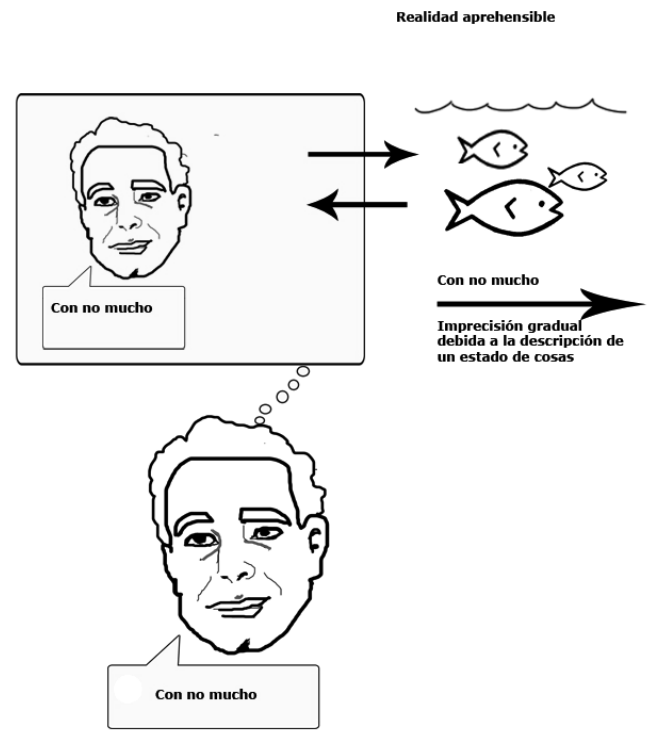

Fig.7

La explicatura de este enunciado sería, por ejemplo, Juan piensa que $P$ donde $\mathrm{P}$ sería exactamente [con no mucho mar en medio]. A partir de ahí existirían una serie de implicaturas escalares del tipo: poco, casi nada, algo, apenas, etc. El problema radica en que, al existir una imprecisión delimitativa, si mucho exigiera un número 4, a partir del 3,99 se entraría en dicho campo de imprecisión. Pongamos un ejemplo visual ${ }^{5}$ :

5 Evidentemente, los números son orientativos y no tienen validez cuantificadora. 


\begin{tabular}{lllllc} 
Nada & Algo & Poco & Bastante & Mucho & Todo \\
\hline-0 & -1 & -2 & 3 & 4 & 5
\end{tabular}

Fig. 8

El uso descriptivo de no mucho implica que el significado impreciso de la secuencia se delimite entre una franja que va desde $-0,1$ al 3,99. Los números que representan a nada, algo y poco son negativos porque indican una carencia, es decir, su significado es descendente dentro de una escala, comparada con el resto de la cadena. Evidentemente, poco será ascendente en relación con algo pero en el cómputo general entra en el campo negativo más cercano a la privación total representada por 0 . Un uso descriptivo del enunciado, donde la forma proposicional de este y la del pensamiento coincidan podría representarse del siguiente modo:

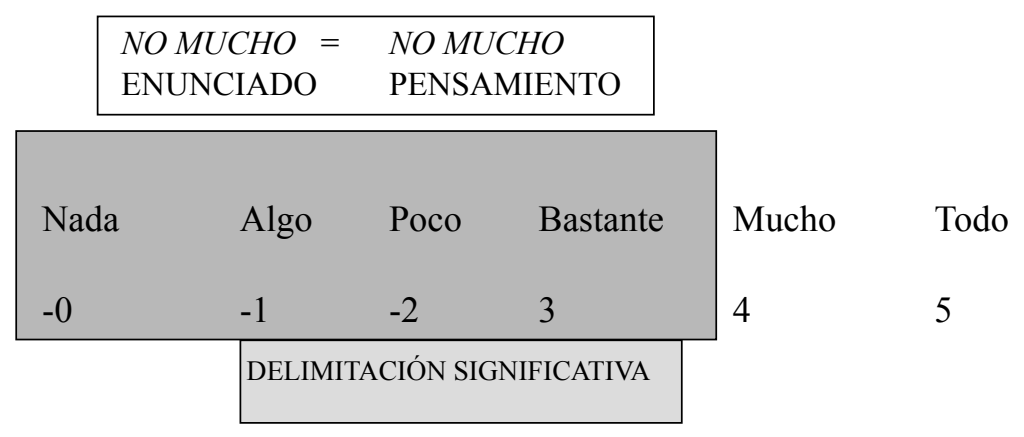

Fig. 9

Ahora bien, desde la Teoría de la Relevancia, el uso de la lítote es más cercano a un uso interpretativo en el que se refleja un pensamiento de segundo orden, precisamente el mismo que acabamos de exponer justo antes; es decir, en la lítote hay que reconocer el enunciado del que nos hacemos eco, o lo que es lo mismo: el enunciado en el que la secuencia negativa es descriptiva $\mathrm{y}$, por tanto, tiene un uso literal.

¿Qué se consigue entonces? Mediante la lítote se consigue precisar una dirección. Según las disquisiciones teóricas de Sperber y Wilson (1990) hay que decir que, en este caso, la partícula no encerraría un contenido procedimental de dirección ascendente o descendente. Así pues, en una secuencia como la anterior, [con no mucho mar en medio] en ningún caso podríamos pensar en [con bastante mar en medio], por ejemplo. Mediante la partícula negativa cambiamos de polo, es decir, desde el polo positivo al negativo. En nuestro ejemplo ilustrativo sería como decir que desde el 
polo en el que se encuentran todo, mucho y bastante se pasa directamente al negativo en el que están nada, poco y algo ${ }^{6}$.

Véase la siguiente figura:

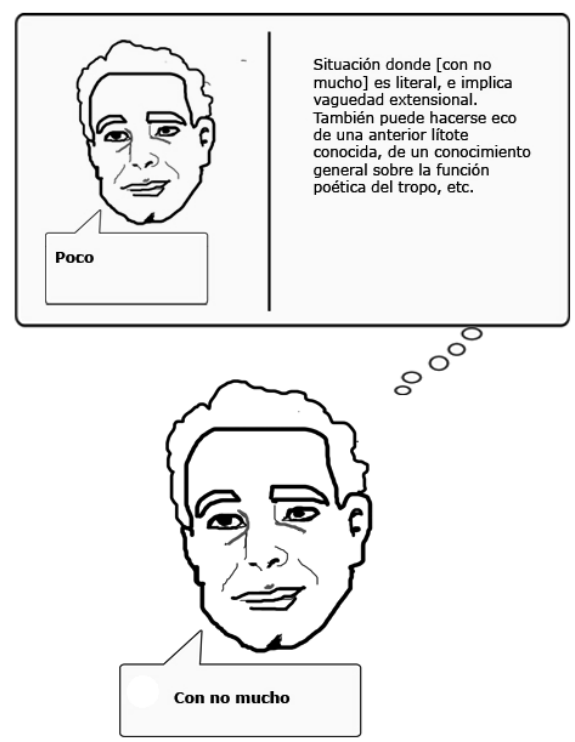

Fig. 10

En este ejemplo, uno se hace eco de la imprecisión del sentido literal y lo que se consigue es utilizar la misma secuencia para expresar un pensamiento que me ofrece una delimitación exacta. Pero aún hay más, los efectos poéticos y las implicaturas débiles que se consiguen mediante este procedimiento no se lograrían de ningún modo. Aquí ya no hay implicaturas escalares como en el anterior caso, sino otro tipo de implicaturas. Por ejemplo: desde una orilla se ve la otra orilla, debe haber pocos peces, puede cruzarse a nado, etc. Dentro de la escala que se apuntaba anteriormente el significado que aparecería en la explicatura del enunciado sería el siguiente:

6 Hay que recordar que este ejemplo es puramente ilustrativo y se pertende convertirlo en paradigma. Son muchos los elementos que pueden encerrarse en un polo positivo y en uno negativo. No solo adjetivos cuantitativos, sino también preposiciones o sustantivos. 


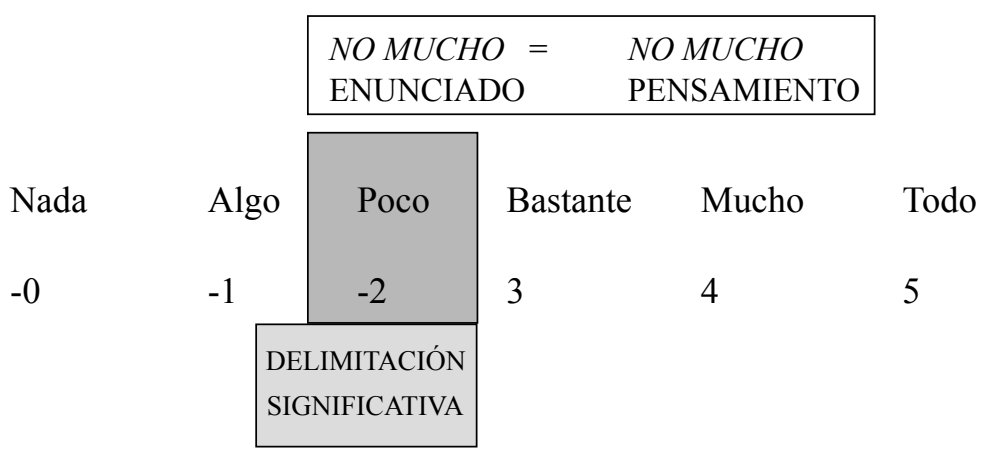

Fig. 11

Ahora bien, ¿y si el hablante quiere transmitir bastante y utiliza esta secuencia? Podría ser que intentara mentir, confundir o, incluso, tranquilizar. Depende de la situación. En este caso, estaría confiando en la buena fe del receptor, que aceptaría poco si lo entendiera como una lítote. Recordemos las siguientes palabras: “...el mundo está lleno de pelmazos. El principio de relevancia no dice que los emisores produzcan estímulos óptimamente relevantes, dice que necesariamente quieren que el destinatario crea que lo hacen. También las personas más pesadas quieren manifiestamente que sus oyentes crean que merece la pena escucharlas" (Sperber y Wilson 1994: 199) En el ejemplo que se comentaba, este uso de la lítote es el óptimamente relevante para el emisor, ya que sabe que lo que él quiere transmitir no es solo bastante, sino que lo que quiere es que el receptor piense bastante cuando él piensa mucho.

Volviendo a lo anterior casi se podría expresar el caso de la lítote mediante una suerte de fórmulas matemáticas. Así pues, cuando se busca postular una dirección ascendente tendríamos que hablar en términos de multiplicación. Es evidente que no es una negación y que por tanto siempre conllevará una carga negativa, su valor, sin embargo, dependerá del contexto y del lugar de la escala al que queramos llegar. Ejemplo:

No poco arte $=$ Mucho arte

$$
[-\mathrm{X} \mathrm{x}-\mathrm{Y}=\mathrm{Z}]^{7}
$$

$-\mathrm{X}=$ no $;-\mathrm{Y}=$ poco $; \mathrm{Z}=$ mucho 
En un caso como el del ejemplo 2 [no sin razón], habría que asignar un valor negativo a la preposición sin, aunque con tener en cuenta que al multiplicar dicho valor con el negativo de la partícula negativa da un resultado positivo (con) es más que suficiente.

Cuando no indica una dirección descendente en la escala no hay que restar, sino dividir. Ya hemos dicho que no tendrá una carga variable según el caso, aunque siempre será negativa. Por tanto, en esta ecuación uno de los elementos del polo positivo se dividirá con un elemento negativo, dando como resultado precisamente otro elemento negativo. En tal sentido, la fórmula sería la siguiente:

No mucho mar $=$ Poco mar

$$
[\mathrm{Y} \%-\mathrm{X}=-\mathrm{Z}]^{8}
$$

Otra explicación la ofrece Levinson. Para este autor, el uso de la lítote rompería la heurística $\mathrm{M}$ que dice: What is said in an abnormal way isn't normal. Desde un punto de vista sintáctico, hay que tener en cuenta que en muchos casos de lítote existe una situación compleja donde llegan a existir tres adyacentes antes del sustantivo. Por ejemplo: [con no poco mar]. Ello produce una implicatura generalizada que concretaría el significado que aporta el recurso retórico, distinto, por otro lado, del significado literal de la expresión. Lo que ocurre es que secuencias como [no poco], [no muy], [no mucho] no parecen tan marcadas y además es una situación característica en nuestra lengua que antes del sustantivo puedan aparecer dos elementos. Además, considerar que sería un caso de implicatura generalizada no explica por qué el emisor decide utilizar tal recurso.

En este caso, como explicaría un relevantista, no es exactamente que se exprese una cosa queriendo decir otra, sino que lo que se dice se precisa y además provoca unas implicaturas que no serían posibles de otra manera.

Por otro lado, postular que hay un reverso semántico como opina Seto para estos casos no parece coherente. Como se ha dicho, lo que se quiere transmitir no es únicamente una cosa mediante la negación de su contrario, sino que es precisamente esa negación la que abre dos caminos: en primer lugar, delimita direccionalmente; $y$, en segundo lugar, consigue un mayor número de implicaciones. Para decirlo de forma resumida, consigue que su enunciado sea más relevante y provoque más efectos en el receptor. Seto 
propone la teoría del reverso semántico para el caso de la ironía, aunque este autor también opina que puede extenderse a otros fenómenos retóricos.

Seto (1998) explica: "there are two types of understatement; one is meiosis and the other litotes (...) Both are a way of emphasis; litotes is different from ordinary double negatives (not unhappy usually does not mean (very) happy)". El ejemplo gráfico del reverso semántico es el siguiente:

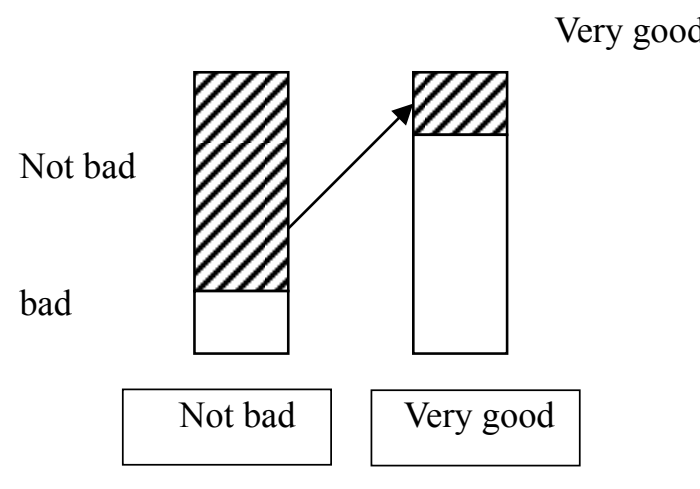

Fig. 12

El paso que hay que dar para conseguir el reverso semántico se realiza mediante lo que Seto (1998) denomina énfasis. Se estaría en este sentido en una situación parecida a la del sarcasmo con lo que se mencionaba de energeia, no es algo que sea fácilmente computable desde un punto de vista lingüístico. ¿En qué consiste el énfasis? Seto no aporta una opinión favorable, de todos modos sería una postura cercana a la de Lausberg. No parece, sin embargo, que la secuencia [no mucho mar] usada como lítote deba significar irremediablemente [poco mar], como habría que pensar desde un punto de vista de reverso semántico. Nosotros, por nuestra parte, preferimos pensar que la lítote es un recurso que nos dirige hacia un polo concreto: el positivo o el negativo. En cada caso, el punto exacto será distinto, aunque seguimos pensando que en ningún caso sería del mismo polo.

Los pasos que definirían el descubrimiento de la lítote serían los siguientes:

1. Reconocer el enunciado ecoico (que es un enunciado descriptivo).

2. Observar que no es una palabra con un contenido procedimental en este caso cuya misión es dirigir hacia uno de los dos polos: el positivo o el negativo. 
3. Descubrir la delimitación exacta del campo significativo (con la ayuda de $n o$ ).

4. Apreciar el gran número de implicaturas débiles que no serían observadas de otra manera.

\subsection{Un PROBLEMA A LA CONSIDERACIÓN ECOICA DE la Teoría de la Relevancia}

Si se considera que el eco es un concepto extenso (broad), implica que los márgenes entre fenómenos se tornan borrosos. En cierto modo, el grueso de los fenómenos retóricos sería ecoico. Por poner un ejemplo, si acepto que en la secuencia [no poco] como lítote me hago eco de [no poco] como uso descriptivo, tendría que aceptar que en [Esta casa es un medio ambiente] me hago eco de la misma secuencia en un uso literal, donde la forma proposicional del enunciado y la del pensamiento fueran la misma.

En la ironía, en la metáfora, en la metonimia no codificada, en la lítote, en el sarcasmo, en el oxymoron, etc, la forma proposicional del enunciado no se corresponde con todo lo que el emisor quiere transmitir y, en la mayoría de ocasiones, se trata de casos donde ambas formas proposicionales difieren aunque tengan una semejanza.

Se vuelve a una noción que se había expuesto más arriba. Al considerar que el eco tiene una delimitación exacta y que las fuentes pueden ser físicas, mentales, reales o inventadas se corre el riesgo de convertir en una noción lingüística infinita el concepto eco.

Este problema es algo que la Teoría de la Relevancia debería estudiar con más detalle de aquí en adelante.

\section{CONCLUSIONES}

Con este trabajo se ha pretendido elaborar un acercamiento a la noción de sarcasmo y de lítote desde un posicionamiento teórico como el relevantista. A algunos estudiosos parece molestarles que dicha teoría compagine criterios lingüísticos con criterios intencionales o actitudes del emisor, es decir, nociones de carácter psicológico.

Así, es cierto que la Teoría de la Relevancia (Sperber y Wilson 1994) es complicada en muchos aspectos porque el ámbito cognitivo juega un gran 
papel y porque, en muchas ocasiones, es difícil dar una explicación lógica o clara al pensamiento y al comportamiento humano.

Ahora bien, al superar la dicotomía literal/figurado como lenguajes distintos, la propuesta relevantista permite entender ciertos fenómenos (ironía, sarcasmo, dobles sentidos, etc.) no como usos propios de una rama distinta y especializada, la Retórica, sino como recursos que pueden ser utilizados por todos los hablantes de una lengua, independientemente de su nivel sociocultural.

Así, las conversaciones cotidianas se tiñen por doquier de ironías, metáforas, sarcasmos, lítotes, etc., y, sin embargo, nadie puede asegurar que las personas que utilizan tales recursos (todo el mundo en realidad) sean poetas que combinan lenguajes diferentes, o, por otro lado, que no consigan comunicarse o hacerse entender. Todo lo contrario; es por tanto asumible que existe un único lenguaje con usos diferentes y que no hay varios lenguajes especializados, sino perspectivas de uso heterogéneas, cuya finalidad prioritaria es mejorar la comunicación cotidiana. 


\section{REFERENCIAS BIBLIOGRÁFICAS}

Attardo, Salvattore. 2000. Irony as relevant inappropriateness. Journal of Pragmatics 32: 793-826.

Azaustre, Antonio y Juan Casas. 1997. Manual de retórica española. Barcelona: Ariel.

CARston, Robert y SEto Uchida (eds.). 1998. Relevance Theory. Applications and Implications. Amsterdam: John Benjamins.

Curcó, Carmen. 2000. Irony: Negation, echo and metarepresentation. Lingua 110: 257 280.

Giora, Rachel. 1995. On irony and negation. Discourse Processes 19: 239-264.

Hamamoto, Hideki. 1998. Irony from a cognitive perspective. En Robyn Carston y Seiji Uchida (eds.), pp. 257-270.

Jorgensen, Julia. 1996. The functions of sarcastic irony in speech. Journal of Pragmatics 26: 613-634.

Lausberg, Heinrick. 1984. Manual de retórica literaria. Madrid: Gredos.

Levinson, Stephen. 1994. Pragmatics. Cambridge: University Press.

Livnat, Zohra. 2003. On verbal irony and types of echoing. UCL Working Papers in Linguistics 15: 71-81.

Pons Bordería, Salvador. 2004. Conceptos y aplicaciones de la Teoría de la Relevancia. Madrid: Arco Libros.

Seto, Ken Ichi. 1998. On non-echoic irony. En Robyn Carston y Seiji Uchida (eds.), pp. 239-255.

SPerber, DAn y Deirdre Wilson. 1990. Rhetoric and relevance. En David Wellbery y John Bender (eds.), pp. 140-155. 1993. Linguistic form and relevance. Lingua 90: 1-25.

1994. Relevancia. Madrid: Visor.

1998. Irony and relevance: A reply to Seto, Hamamoto and Yamanashi. En Robyn Carston y Seiji Uchida (eds.), pp. 283-293.

Torres Sánchez, María Ángeles. 1999. A propósito de la ironía ecoica. Ponencia presentada en III Simposio Andaluz de Lingüística General. Sevilla: España.

Wellbery, David y John Bender (eds.). 1990. The Ends of Rhetoric: History, Theory, Practice. Stanford: University Press.

Yamanashi, M. 1998. Some issues in the treatment of irony and related tropes. En: Robyn Carston y Seiji Uchida (eds.), pp. 271-281. 